\title{
Why and How to Support Students in Team Assignments
}

Innovations in Teaching and Learning Conference

September 16, 2016

M ASON School of Business 


\section{Challenges of Teamwork}

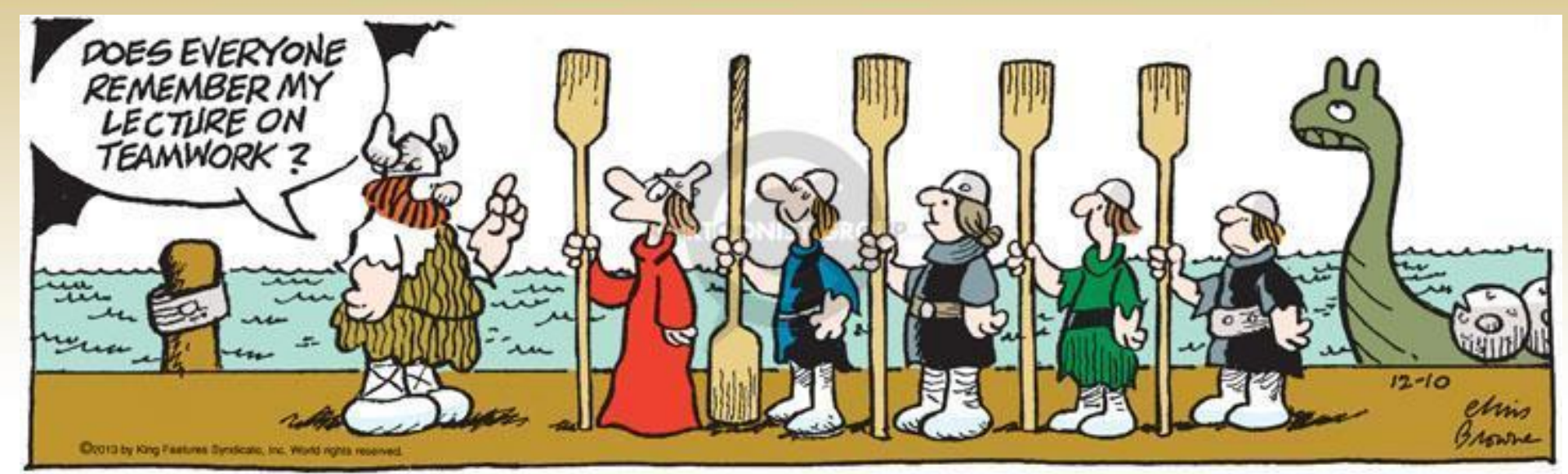

OKing Features Syndicate

Challenges for Faculty:

$>$ How to Teach "Teamwork" Skills

$>$ How to Organize Team Projects

> How to Assess Student Participation 


\section{Challenges of Teamwork}

Challenges for Students:

$>$ No Team Identity

$>$ Unclear Roles

> Poor Communication

$>$ Lack of Planning

$>$ Non-Participation

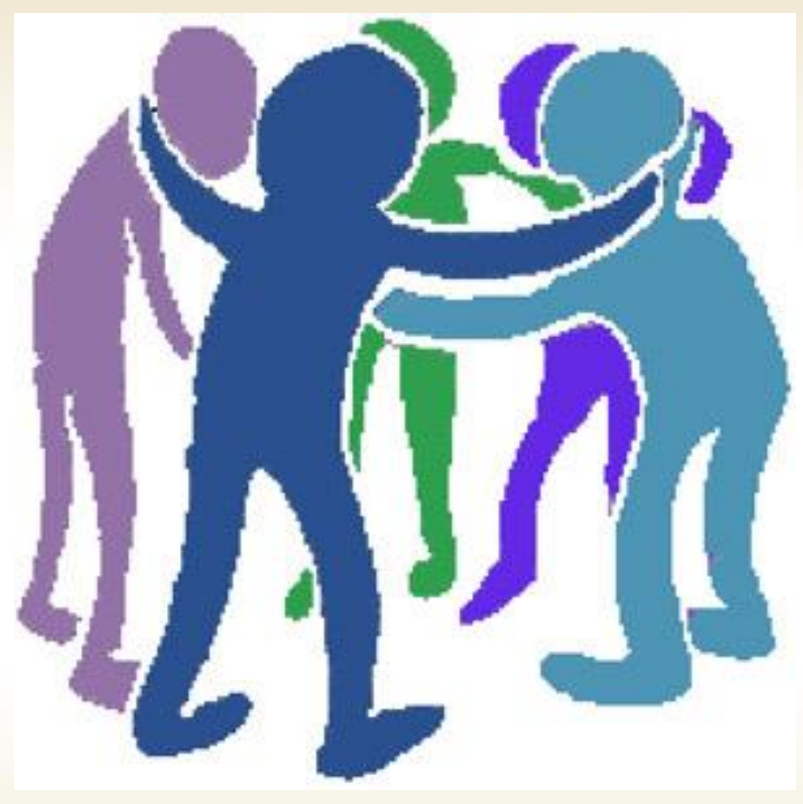




\section{Why Teamwork?}

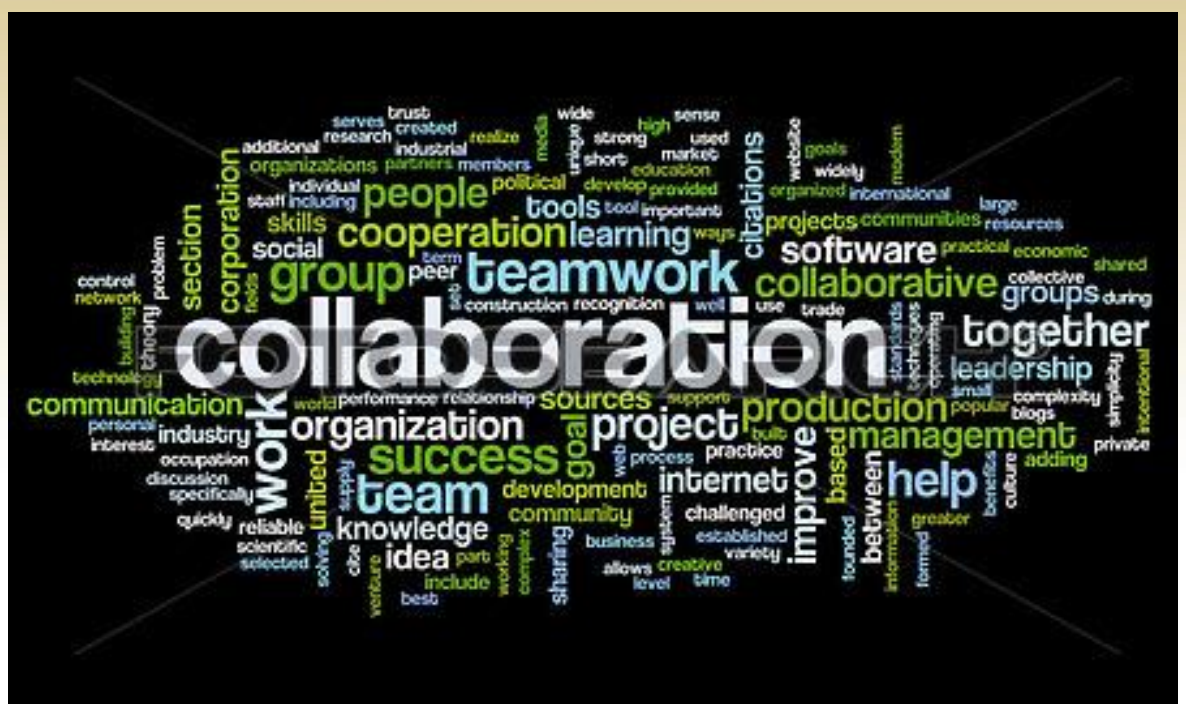

Teamwork is an essential learning element in college because:

$>$ Employers value teamwork skills highly

$>$ Students need teamwork skills in work and in life 


\section{Why Teamwork?}

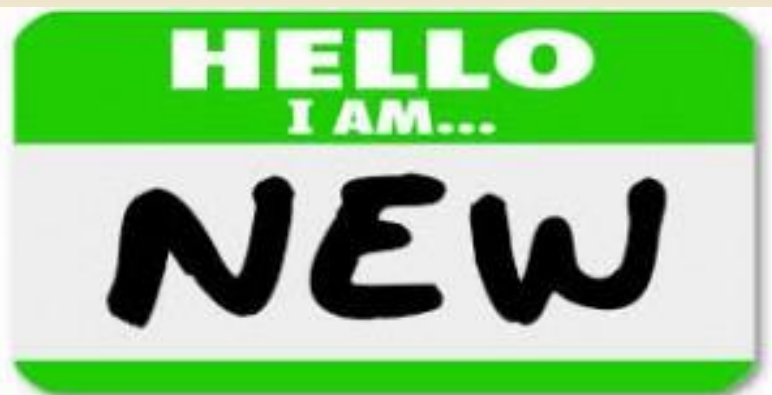

Role Play: What will NOT Happen on the First Day at Work ... 


\section{Employer Perspective}

The National Association of Colleges and Employers, in their annual survey of employers, consistently finds:

"teamwork skills" and the ability to work with others are among the top 5 qualities employers

most desire in employees.

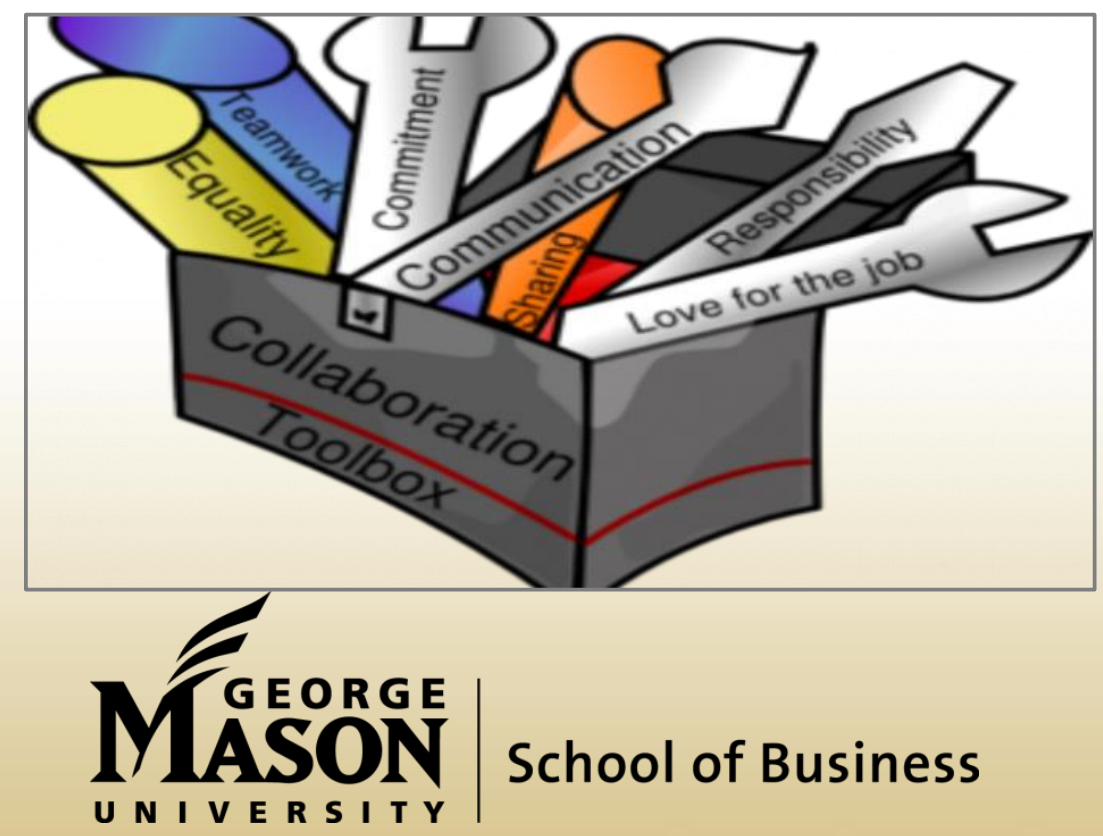




\section{Employer Perspective}

Society for Human Resource Management lists these key competencies that employers seek:

Business Acumen

Communication

Consultation

Critical Evaluation

Ethical Practice

Global and Cultural Effectiveness

Leadership and Navigation

Relationship Management

YASON School of Business 


\section{Teamwork as a Soft Skill}

Common Soft Skills on Job Descriptions

$>$ Team Player

$>$ Collaboration

$>$ Communication

$>$ Interpersonal Skills

$>$ Client Focus

$>$ Project Management

$>$ Creative Problem Solving 


\section{Communication}

\section{Communication Challenges:}

$>$ Inability to Listen

$>$ Cultural Differences

$>$ Use of Technical Language and Jargon

$>$ Mode: in Person, Text, Email, Virtual Meeting

$>$ Use of Non-Constructive Feedback

"The greatest problem with communication is the illusion that it has been accomplished." George Bernard Shaw 


\section{Virtual Teams}

\section{Factors increasing the use of Virtual Teams:}

$>$ Globalization of Business and World Markets

$>$ Decentralization of Corporations and Organizations

$>$ Advances in Communication Technology

$>$ Reduction in Travel Budgets for Employees

$>$ High Cost of Classroom Training Delivery

$>$ Desire to Leverage Talent across Boundaries 


\section{We Know How Teams Work!}

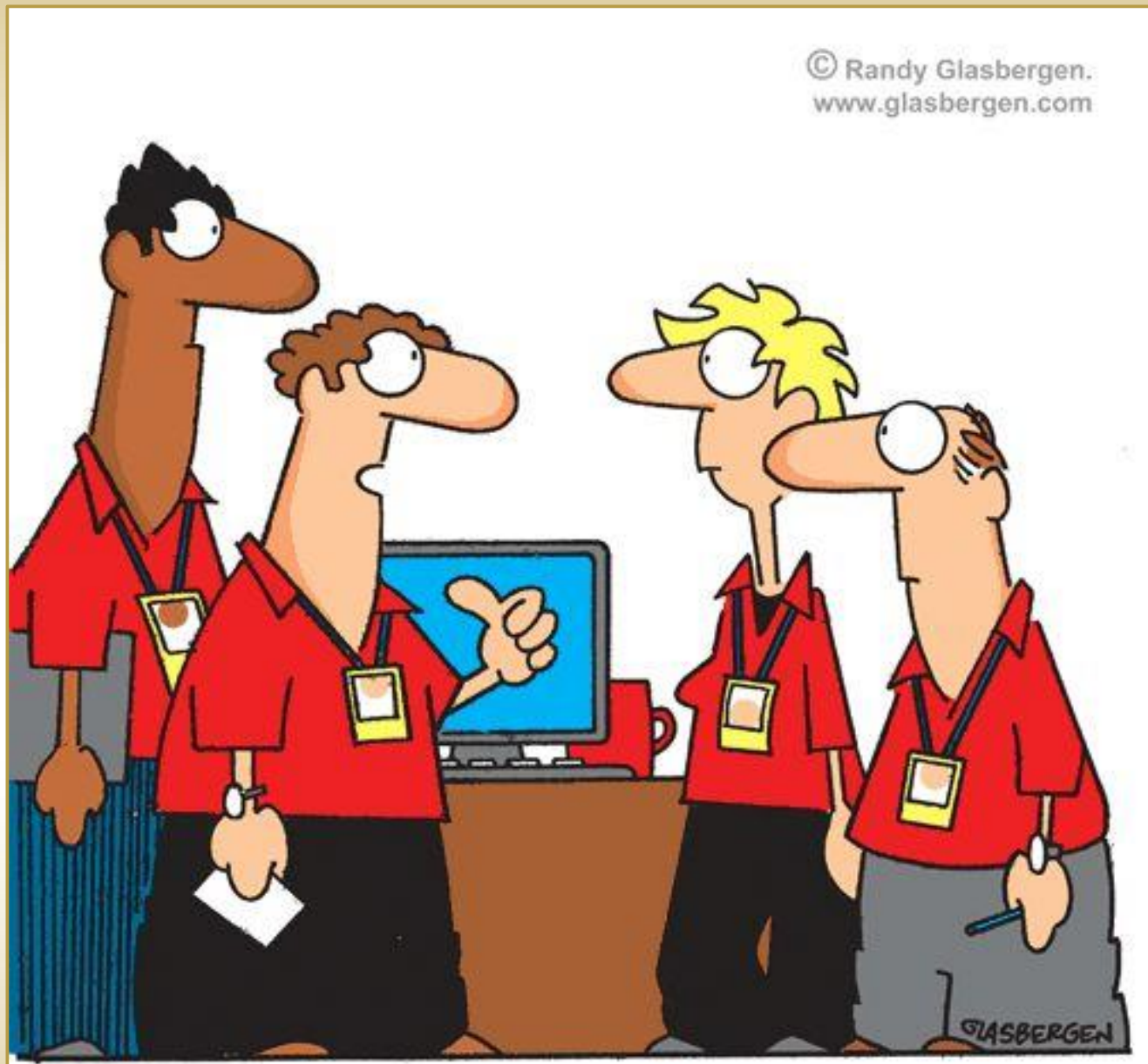

"How can you say we're not behaving like a team? We're all wearing the same color shirts, aren't we?" 


\section{What makes a Team Fail?}

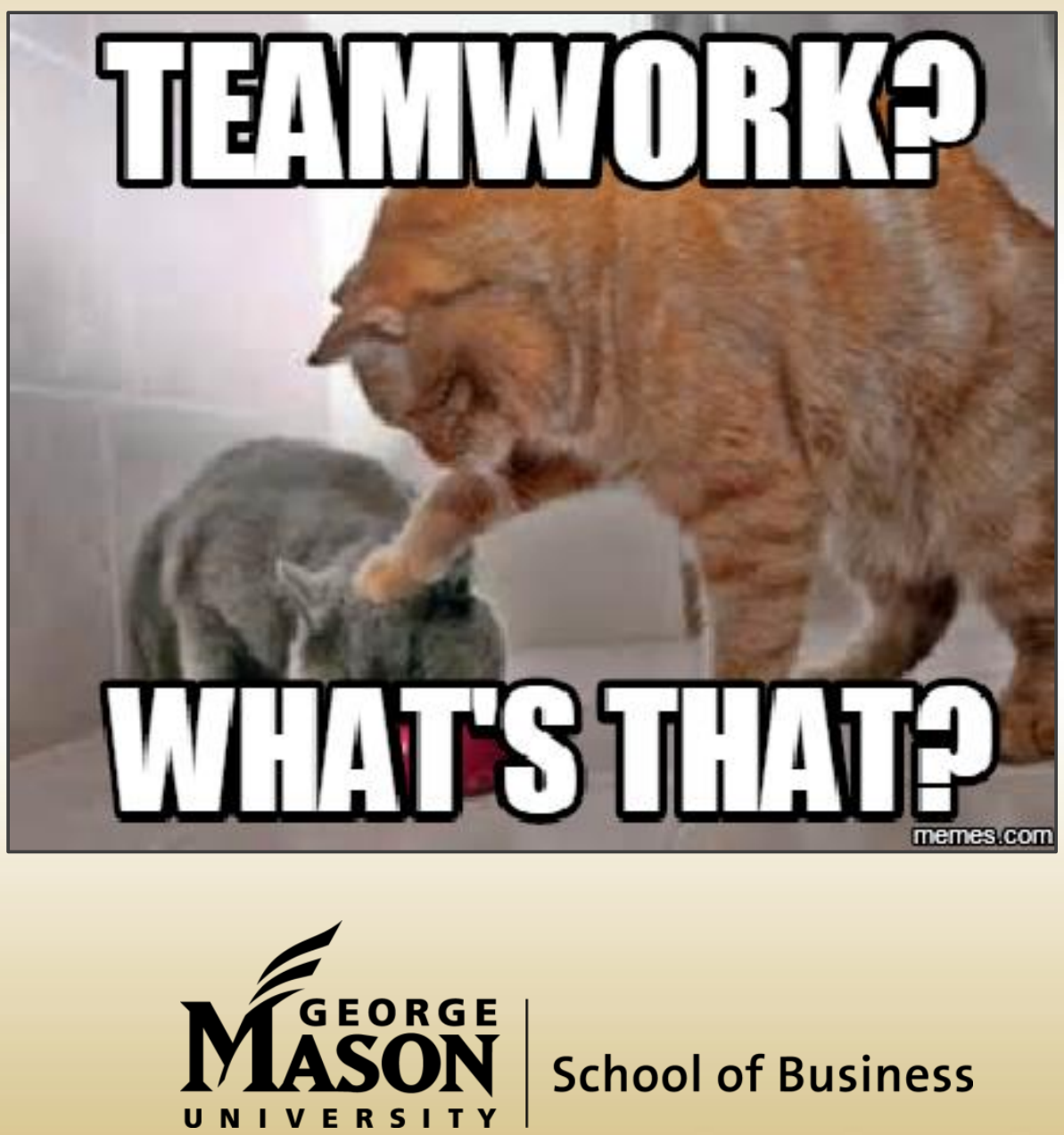




\section{Stages of Team Development}

1. Forming - Getting acquainted. Group is

harmonious at this time, but no team identity has yet been developed.

2. Storming - Conflicts begin as team members negotiate assignments, project management, and how to communicate. This is a vital phase.

3. Norming - Team has set up shared goals, some roles, and rules of conduct. Team begins to be productive, and a sense of team pride develops.

4. Performing - Group settles into a functional team

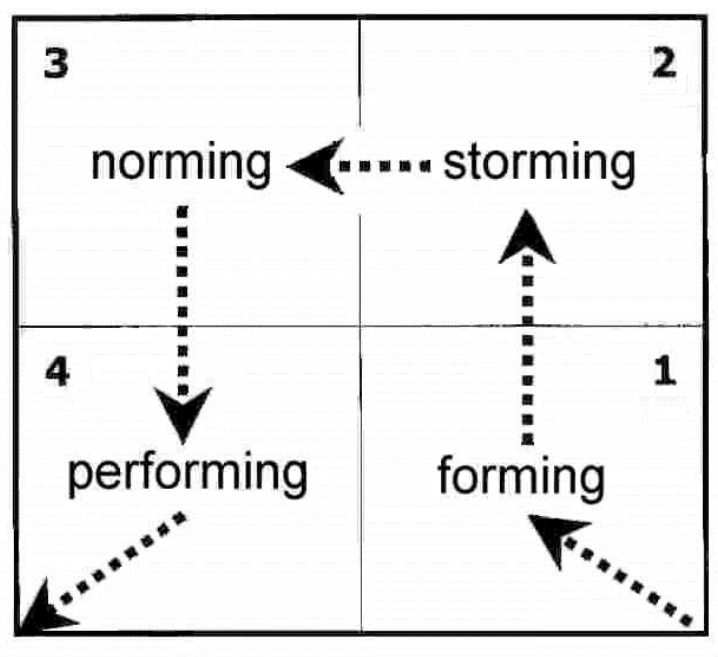
and now the work on an assignment can get done.

School of Business 


\section{Value of Teamwork}

Tip \#1: Show Students the Value of Learning Teamwork Skills

For example, students can:

$>$ Research the employer perspective

$>$ Create a chart showing the benefits of teamwork

$>$ Read articles on team success and failure

$>$ Read a case study which highlights a team success

$>$ Read "The Five Dysfunctions of a Team" 


\section{What is Teamwork?}

Tip \#2: Explore the Topic of Teamwork with your Students

For example, students can:

$>$ Read and respond to library articles on teamwork

$>$ View a video about teamwork and team strategy

$>$ Describe the roles needed for a successful team

$>$ Reflect on previous good and bad team experiences

$>$ Participate in a discussion on the topic of teamwork

$$
\begin{array}{lll}
\text { Working in Teams } & \\
\hline \multicolumn{1}{|c|}{\begin{array}{l}
\text { Name: } \\
\text { Duration: }
\end{array}} & \text { Working in Teams } \\
\text { Added: } & 21: 09 \\
\text { Added By: } & \text { Dr. JK Aier } \\
\text { Description: } & \\
\text { Tags: } &
\end{array}
$$




\section{What is Teamwork?}

Tip \#2 (cont.): Explore the Topic of Teamwork with your Students

\section{Readings}

- Read "The Five Dysfunctions of a Team: A Leadership Fable," by Patrick Lencioni. This book is an easy read, and you should find it entertaining as well as informative. It is available online for free through Safari Books. The link for the book is provided below through the Mason Online Library System.

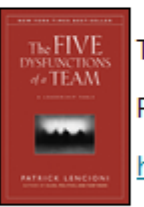

The Five Dysfunctions of a Team: A Leadership Fable

Pages in Print Edition: 240 pages

http://proquest.safaribooksonline.com.mutex.gmu.edu/9780787960759

- Skim the two articles about best practices for virtual teams, which are available through Mason University Libraries and provided below. - ACCT 690 - Reading - Finding Common Ground.pdf

- ACCT 690 - Reading - Challenges to Virtual Teams.pdf 


\section{From a Group to a Team}

Tip \# 3: Provide Tools for Students to Build an Operational Team

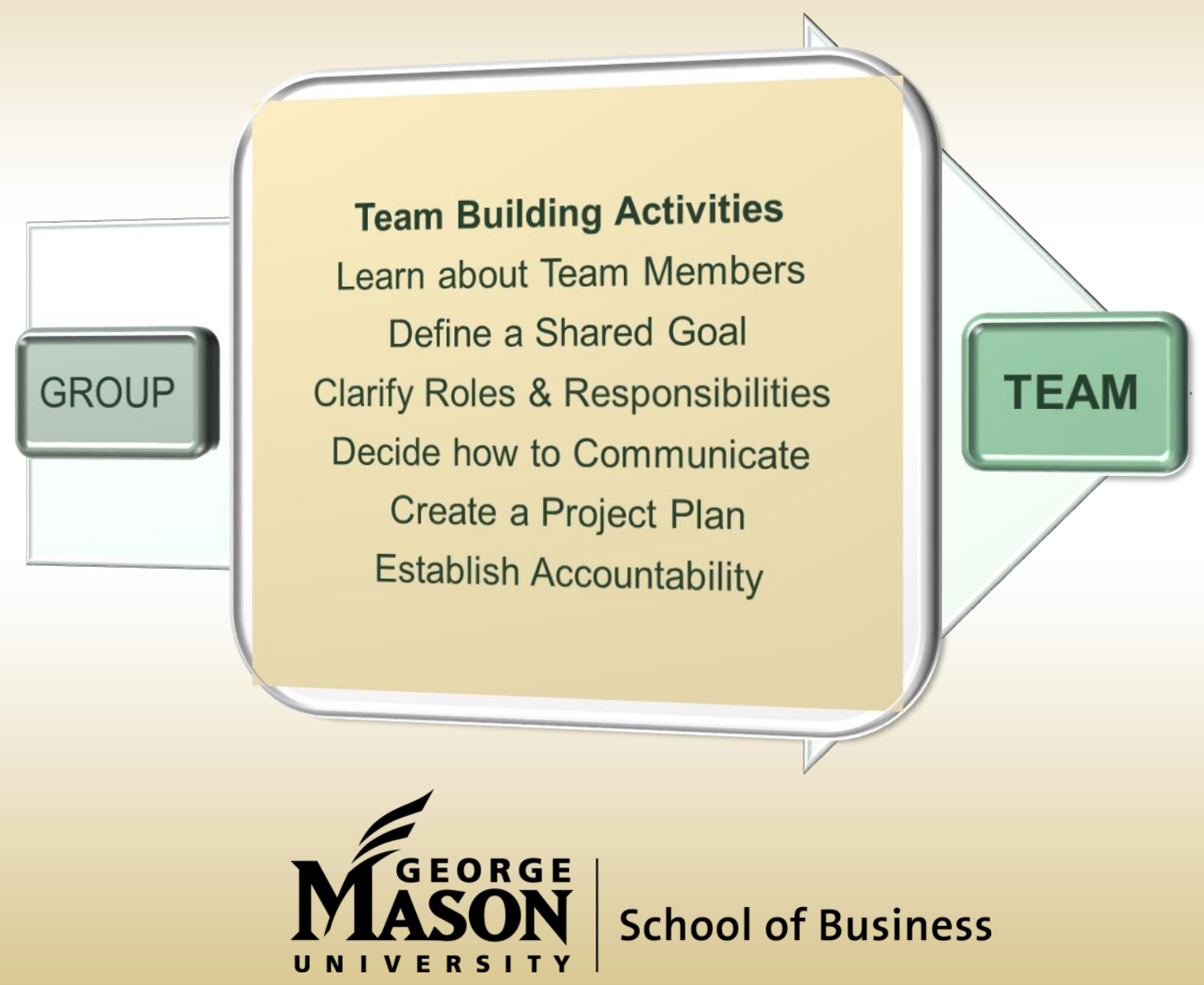




\section{How to Build a Team}

Tip \#4: Enable Students to Build a Team before starting Assignment

For example, students can:

$>$ Read library articles on teamwork

Working in Teams

Name:

Duration:

Added:

Added By:

Watch Video Description

Working in Teams

21:09

Dr. JK Aier

$>$ View a video about teamwork and team strategy

$>$ Describe the roles needed for a successful team

$>$ Reflect on previous good and bad team experiences

$>$ Participate in a discussion on the topic of teamwork 


\section{How to Build a Team}

\section{Tip \#4 (cont.): Enable Students to Build a Team before starting Assignment}

\section{Team Activity and Team Charter}

Attached Files: 9 Team Activities.pdf (25.712 KB)

$\square$ Team Charter Examples.pdf (34.352 KB)

You will be pre-assigned to a Team. View your Team Members in the "Team Workspace" area. Use the Group Tools in the Workspace for the discussions necessary to complete the team activities

\section{Articles on Virtual Teams}

The two articles about best practices for virtual teams are available through Mason University Libraries. Please follow the course e-reserve link.

Team Scavenger Hunt Activity

The Scavenger Hunt activity provides a way for you and your teammates to work together without the pressure of a "grade so that you can get to know each other and begin to discover the team members' strengths and weaknesses. This activity and the Team Charter discussion will be completed synchronously. You are required to participate in a live team session - at a time determined by you and your teammates.

Only one member of your team should complete the Hunt questions, although you will all work on the questions together. You should choose now who is going to be the one person to complete the Hunt for your team. When you have chosen one person, they can click here to access the Scavenger Hunt Clues and to post your group's responses.

\section{Team Charter Assignment}

In addition to learning about how to create a Team Charter, this assignment introduces you to SafeAssign on Blackboard. SafeAssign is a plagiarism education and prevention service available through Blackboard. While only one team member will be submitting the Team Charter, all team members should design the Team Charter together. All team members should read more about SafeAssign here.

\section{School of Business}




\section{Team Charter Outline}

Tip \#4 (cont.): Enable Students to Build a Team before starting Assignment

\section{Team Charter}

A. Mission

B. Operating Plan

- Participation

- Communication

- Meetings

- Roles

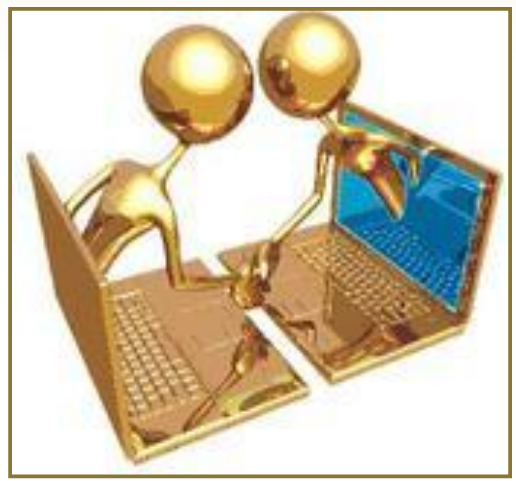

- Accountability

C. Signature Block 


\section{Project Management}

Tip \#5: Use these Strategies to Manage Team Projects

For example:

$>$ Students create an Outline or Gantt Chart for Project

$>$ Students divide work by Roles or by Content

$>$ Instructor "chunks" Project work into sections

> Instructor has multiple deliverables over Project timeline

$>$ Instructor includes an Individual deliverable in the Project

$>$ Students evaluate each other's Participation in the Team

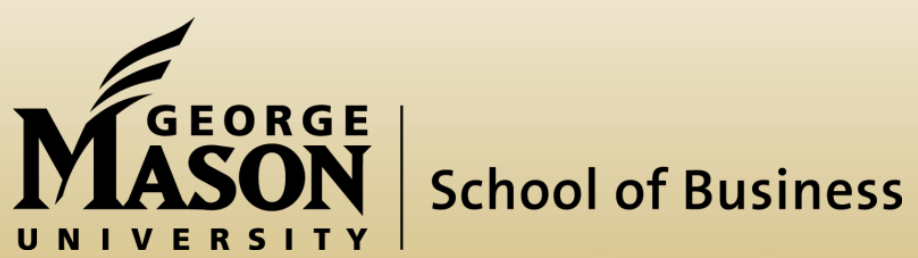




\section{Project Management: Chunking}

\section{Tip \#5 (cont.): Use these Strategies to Manage Team Projects}

\section{Deliverables for International Expansion Group Project:}

- Gantt chart: Your team's chart will detail each step of this project, with a start and end dates for each step. List who is responsible for each step. See Creating a Gantt Chart sheet for instructions.

- Report: Your team report of about 5,000 words persuades senior management to send a site team to the country you recommend. The report include all the standard elements of a business report. See Report Guidelines sheet for details.

- Presentation: Your team will deliver a PowerPoint presentation to your company's senior management to persuade them to send a site team to your recommended country. The presentation will be 20 minutes long; each team member must speak for about the same amount of time.

- Press release: Individually, write a press release announcing that your company is going to expand to your selected country: open a factory, sell products, open stores, etc. The audience for this press release is readers in the expansion country. You are not writing for an American audience. 


\section{Project Management: Peer Evaluation}

Tip \#5 (cont.): Use these Strategies to Manage Team Projects

\section{Week 13}

Team Paper Peer Evaluation

Team Paper Peer Evaluation

Click on the icon below to download the Peer Evaluation Rubric. As part of the final participation grade for the term, each member of the group will evaluate the participation and contributions of the other group members. This assessment in conjunction with a faculty analysis of your contributions to the group collaborative space and group assignments will comprise your final participation grade. Participation is worth $5 \%$ of your overall course grade.

PeerEvaluation-Online Classes.doc 


\section{Summary}

\section{Teamwork Tips for Instructors}

$>$ Show Students the Value of Learning Teamwork Skills

$>$ Explore the Topic of Teamwork with your Students

$>$ Provide Tools for Students to Build an Operational Team

$>$ Enable Students to Build a Team before starting Assignment

$>$ Use these Strategies to Manage Team Projects:

$>$ Outline or Gantt Chart

$>$ Students assign Roles

$>$ Chunk the Project Work
$>$ Divide work into Multiple Deliverables

$>$ Include an Individual Deliverable

$>$ Use Peer Evaluations 


\section{Thank you!}

Judith Stevenson

Instructional Designer and Technologist

School of Business:

(703) 993-1889

jstevenb@gmu.edu 